\title{
The Conditions of Ovary Storage Affect the Quality of Porcine Oocytes
}

\author{
Matías Nicolás Tellado, Gabriel Martín Alvarez*, Gabriel Carlos Dalvit, Pablo Daniel Cetica \\ Area of Biochemistry, INITRA (Institute of Research and Technology in Animal Reproduction), School of \\ Veterinary Sciences, University of Buenos Aires, Buenos Aires, Argentina \\ Email: *galvarez@fvet.uba.ar
}

Received 4 June 2014; revised 5 July 2014; accepted 22 July 2014

Copyright @ 2014 by authors and Scientific Research Publishing Inc.

This work is licensed under the Creative Commons Attribution International License (CC BY).

http://creativecommons.org/licenses/by/4.0/

(c) (i) Open Access

\section{Abstract}

We studied the effect of different storage conditions of porcine ovaries (time, temperature) on the characteristics of the follicular fluid, immature oocyte quality, meiotic competence and in vitro fertilization of oocytes. Ovaries were stored for 2,4 or $6 \mathrm{~h}$ at 3 different temperatures $\left(15^{\circ} \mathrm{C}, 25^{\circ} \mathrm{C}\right.$ or $35^{\circ} \mathrm{C}$ ). As the storage time increased, $\mathrm{pH}$ and glucose concentration of the follicular fluid, percentage of live immature oocytes at germinal vesicle stage, oxidative activity and maturation rate decreased. At higher temperatures, $\mathrm{pH}$ and glucose concentration decreased, but oxidative activity and oocyte maturation rate increased. Lactate concentration and immature oocyte ROS production increased as storage time and temperature increased. The ovary storage for longer than $\mathbf{2} \mathrm{h}$ at $25^{\circ} \mathrm{C}$ and $35^{\circ} \mathrm{C}$ resulted in low $\mathrm{pH}$ of the follicular fluid and high ROS level in immature oocytes. Such conditions seem to damage oocytes and impair their meiotic competence. A decrease in the oxidative activity caused by long time and/or low storage temperature may imply a decrease in oocyte vitality. In conclusion, in the porcine species, the transport of ovaries at $25^{\circ} \mathrm{C}$ and $35^{\circ} \mathrm{C}$ for 2 $\mathrm{h}$ are the best conditions to maintain adequate oocyte quality, meiotic competence and in vitro fertilization rates.

\section{Keywords}

Ovary Storage, Oocyte Quality, Pig

\section{Introduction}

Ovaries from slaughtered females constitute the main source of oocytes for laboratory use in domestic animals. In general, slaughterhouses are several kilometres away from the laboratory and ovaries must be preserved for

\footnotetext{
"Corresponding author.
}

How to cite this paper: Tellado, M.N., Alvarez, G.M., Dalvit, G.C. and Cetica, P.D. (2014) The Conditions of Ovary Storage Affect the Quality of Porcine Oocytes. Advances in Reproductive Sciences, 2, 57-67. 
long periods of time before oocytes are collected. This fact has a different impact on oocyte quality in several livestock species. In horses, nuclear maturation is not affected by the storage of ovaries at $27^{\circ} \mathrm{C}-37^{\circ} \mathrm{C}$ for $6-8$ $\mathrm{h}$ [1], whereas the maturation rates of sheep oocytes decrease with the increase in ovaries storage time [2]. In dogs, the temperature at which ovaries are transported does not affect oocyte meiotic competence [3]. However, in bovines, oocytes obtained from ovaries preserved at $37^{\circ} \mathrm{C}$ for $8 \mathrm{~h}$ or at $4^{\circ} \mathrm{C}$ for 12 or $24 \mathrm{~h}$ show significantly lower cleavage and blastocyst formation rates after in vitro culture [4] [5]. In cats, the storage of ovaries at $4^{\circ} \mathrm{C}$ for 2 and $24 \mathrm{~h}$ does not affect oocyte meiotic competence in vitro, but results dramatically decrease with $48 \mathrm{~h}$ storage [6], while in pigs the decrease can be detected in oocyte in vitro maturation and embryo development after in vitro fertilization or electric activation at storage temperatures below $15^{\circ} \mathrm{C}$ or for periods longer than $6 \mathrm{~h}$ [7] [8]. However, the studies cited above do not clarify the mechanisms involved in the oocyte damage induced by these storage conditions.

An oocyte enclosed within the follicle must remain metabolically active while it is being transported from the slaughterhouse to the laboratory in order to develop in vitro. Cell metabolism depends on enzymatic activity, which is in turn temperature-dependent [9]. The analysis of porcine and bovine follicular fluid composition has shown a slightly lower than plasma glucose concentration [10] [11]. Glycolysis is a universal oxidative pathway of glucose catabolism and, under anaerobic conditions, lactate is its final product [12]. During the transport to the laboratory, the occlusion of blood flow reduces oxygen supply to ovaries, placing them under ischemic conditions [7].

Some studies have shown that oxidative stress during in vitro culture causes alterations in bovine and murine oocytes that impair their maturation and developmental competence [13] [14]. Moreover, it is known that reactive oxygen species (ROS) can cause DNA damage and induce apoptosis in human and porcine oocytes cultured in vitro [15] [16].

The RedoxSensor Red CC1 assay is a stain used to determine cell redox potential. This technique has been successfully used in bovine embryos to document the relationship between the redox flux and oxygen consumption [17]. The relationship between substrate availability and mouse oocyte redox potential has also been demonstrated [18]. The reduced oxygen supply during ovaries transport could modify redox potential and increase ROS production in porcine oocytes. The pig's body temperature ranges from $38^{\circ} \mathrm{C}$ to $39.5^{\circ} \mathrm{C}$ [19]. By reducing the temperature of ovary storage to $35^{\circ} \mathrm{C}, 25^{\circ} \mathrm{C}$ and $15^{\circ} \mathrm{C}$ respectively we would expect cell metabolism to decrease consequently.

We hypothesize that the changes in follicular metabolism which occur during ovary transport from the slaughterhouse to the laboratory can modify follicular fluid and thus affect oocyte quality. Therefore, the aim of the present work was to evaluate the effect of different storage conditions, as regards time and temperature, on selected follicular fluid parameters ( $\mathrm{pH}$, glucose and lactate concentrations) derived from ovaries obtained from slaughtered gilts. We also aimed at evaluating the influence of those factors on the nuclear status, live/dead rate, oxidative activity and ROS concentration in gilt oocytes as well as oocyte quality reflected by meiotic competence and in vitro fertilization.

\section{Materials and Methods}

\subsection{Materials}

Unless otherwise specified, all chemicals used were purchased from the Sigma Chemical Company (St. Louis, MO, USA).

\subsection{Transport Conditions of Ovaries}

Ovaries from gilts at age 5 - 6 months (about $100 \mathrm{~kg}$ ) were obtained from a local slaughterhouse and transported in $0.9 \%(\mathrm{w} / \mathrm{v}) \mathrm{NaCl}$ containing 100,000 IU/L penicillin and $100 \mathrm{mg} / \mathrm{L}$ streptomycin. Ovaries were randomly assigned to one of nine groups (approximately 15 ovaries per group): stored at $15^{\circ} \mathrm{C}$ for $2 \mathrm{~h}, 4 \mathrm{~h}$ and $6 \mathrm{~h}$; stored at $25^{\circ} \mathrm{C}$ for $2 \mathrm{~h}, 4 \mathrm{~h}$ and $6 \mathrm{~h}$ and stored at $35^{\circ} \mathrm{C}$ for $2 \mathrm{~h}, 4 \mathrm{~h}$ and $6 \mathrm{~h}$.

\subsection{Analysis of Porcine Follicular Fluid: Ph, Glucose and Lactate Concentration of the Follicular Fluid}

Porcine follicular fluid was aspirated from 3 - $8 \mathrm{~mm}$ antral follicles immediately after the storage of ovaries for 
the different times and temperatures described above. About $2 \mathrm{ml}$ follicular fluid obtained from a single ovary was disposed in an Eppendorf tube and its $\mathrm{pH}$ was measured three times within 3 min after collection using a digital $\mathrm{pH}$ meter ( $\mathrm{pH}$ Boy-P2, Shindengen electric, Japan). The mean $\mathrm{pH}$ value of the three replicates was chosen for each sample. After $\mathrm{pH}$ measurement, follicular fluid was stored at $-80^{\circ} \mathrm{C}$ until glucose and lactate concentration determination. Glucose concentration in the follicular fluid was measured using a spectrophotometric assay based on glucose oxidation by glucose oxidase and the subsequent determination of hydrogen peroxide formation [20] [21]. Lactate concentration in the follicular fluid was measured in a similar manner, using lactate oxidase [20].

\subsection{Recovery and Selection of Cumulus-Oocyte Complexes (Cocs)}

Cumulus-oocyte complexes were aspirated from 3 - $8 \mathrm{~mm}$ antral follicles using a $10 \mathrm{~mL}$ syringe and an $18-$ gauge needle, and oocytes surrounded by a multilayer and dense cumulus were selected. We recovered an average of 20 oocytes per ovary.

\subsection{Oocyte Denudation}

Immature oocytes were denuded of somatic cells by vortex agitation for 1 min at $37^{\circ} \mathrm{C}$ in $3 \mathrm{~g} / \mathrm{L}$ bovine serum albumin (BSA) in phosphate buffered saline (PBS) consisting of $136.9 \mathrm{mM} \mathrm{NaCl}, 2.7 \mathrm{mM} \mathrm{KCl}, 8.1 \mathrm{mM}$ $\mathrm{Na}_{2} \mathrm{HPO}_{4}$, and $1.7 \mathrm{mM} \mathrm{KH}_{2} \mathrm{PO}_{4}(\mathrm{pH} 7.35$ - 7.65) and they were then separated from the remaining cumulus cells with a Pasteur pipette.

In vitro matured COCs were incubated in $1 \mathrm{~g} / \mathrm{L}$ hyaluronidase in PBS for $5 \mathrm{~min}$ at $37^{\circ} \mathrm{C}$ and oocytes were denuded by gentle pipetting.

\subsection{Evaluation Vitality and Nuclear Stage of Immature Oocytes}

Once denuded, immature oocytes were divided into two groups to evaluate their vitality and nuclear stage. To assess their vitality, oocytes were incubated for $10 \mathrm{~min}$ at $37^{\circ} \mathrm{C}$ in $2.5 \mu \mathrm{g} / \mathrm{L}$ fluorescein diacetate fluorochrome in PBS. Oocytes were washed in PBS before being observed with an epifluorescence microscope (using 450 - 490 $\mathrm{nm}$ and $520 \mathrm{~nm}$ excitation and emission filters respectively) at 100× magnification (active estearases present in live oocytes hydrolyse the fluorochrome to render a green fluorescent compound) [22] [23].

To assess nuclear stage, oocytes were centrifuged at $8200 \mathrm{~g}$ for $30 \mathrm{~min}$ to polarize lipids and then incubated in $5 \mathrm{mg} / \mathrm{L}$ Hoechst 33,342 fluorochrome in PBS for $30 \mathrm{~min}$ at $37^{\circ} \mathrm{C}$. After being washed in PBS, oocytes were observed with an epifluorescence microscope (using 330 - $380 \mathrm{~nm}$ and $420 \mathrm{~nm}$ excitation and emission filters respectively) to evaluate chromatin configuration [24] and with a Nomarsky differential-interferential contrast microscope at $100 \times$ and $400 \times$ magnification to evaluate the presence or absence of the nuclear membrane (the germinal vesicle stage was identified by the co-localized fluorescent nuclear material and the nuclear membrane) [22].

\subsection{Oocyte in Vitro Maturation}

The COCs were cultured in medium 199 (Earle’s salts, L-glutamine, $2.2 \mathrm{mg} / \mathrm{L}$ sodium bicarbonate; GIBCO, Grand Island, NY, USA) supplemented with $10 \%$ (v/v) foetal bovine serum (GIBCO), $0.57 \mathrm{mM}$ cysteine, 50 $\mathrm{mg} / \mathrm{L}$ gentamicin sulphate, and $0.5 \mathrm{mg} / \mathrm{L}$ porcine follicle-stimulating hormone (FSH) (Folltropin-V, Bioniche, Belleville, Ontario, Canada) plus $0.5 \mathrm{mg} / \mathrm{L}$ porcine luteinizing hormone (LH) (Lutropin-V, Bioniche) under mineral oil at $39^{\circ} \mathrm{C}$ for $48 \mathrm{~h}$ in a $5 \% \mathrm{CO}_{2}$ atmosphere [25]. Groups of about $50 \mathrm{COCs}$ were matured in $500 \mu \mathrm{l}$ culture medium.

\subsection{In Vitro Fertilization}

In vitro fertilization was performed using fresh semen from a Yorkshire boar of proven fertility. Sperm-rich fractions were collected using the gloved-hand method [26]. Sperm samples were washed twice in PBS added with $3 \mathrm{~g} / \mathrm{L}$ BSA by centrifugation at $400 \mathrm{~g}$ for $5 \mathrm{~min}$. Pellets were re-suspended in fertilization medium (modified Tris-buffered medium, consisting of $113.1 \mathrm{mM} \mathrm{NaCl}, 3 \mathrm{mM} \mathrm{KCl}, 10 \mathrm{mM} \mathrm{CaCl}_{2}, 20 \mathrm{mM}$ Tris, $11 \mathrm{mM}$ glucose, $5 \mathrm{mM}$ sodium pyruvate, $4 \mathrm{~g} / \mathrm{L}$ bovine serum albumin, $2.5 \mathrm{mM}$ caffeine and $50 \mathrm{mg} / \mathrm{L}$ gentamicin sulfate) 
[27]. Samples were filtered through a 20-mg glass wool column (10 mm high, $4 \mathrm{~mm}$ in diameter), previously washed with a modified Tris-buffered medium, to obtain the motile fraction [28]. Matured COCs were denuded and inseminated with a final concentration of $5 \times 10^{8} / \mathrm{L}$ spermatozoa. Gametes were co-incubated in modified Tris-buffered medium under mineral oil at $39^{\circ} \mathrm{C}$ for $18 \mathrm{~h}$ in a $5 \% \mathrm{CO}_{2}$ atmosphere.

\subsection{Evaluation of Oocyte Maturation}

After culture, oocytes were denuded, placed in a hypotonic medium containing $10 \mathrm{~g} / \mathrm{L}$ sodium citrate at $37^{\circ} \mathrm{C}$ for $15 \mathrm{~min}$, fixed on a slide with Carnoy fixing solution (3:1 ethanol: acetic acid), and stained with $5 \%$ (v/v) Giemsa (Merck, Darmstadt, Germany) for 15 min. They were then observed under a light microscope at $100 \times$ and $400 \times$ magnifications. Oocytes which presented a filamentous chromatin located throughout the area of the germinal vesicle or bivalent chromosomes (methaphase I) were considered immature, while those which showed metaphase II chromosome configuration were considered meiotically mature (Figure 1) [22].

Presumptive zygotes were freed from attached spermatozoa by repetitive pipetting, fixed on a slide with Carnoy fixing solution for at least $24 \mathrm{~h}$, incubated in an aqueous $10 \mathrm{mg} / \mathrm{L}$ Hoechst 33,342 solution for $15 \mathrm{~min}$ at room temperature, and observed under an epifluorescence microscope (using 330 - $380 \mathrm{~nm}$ and $420 \mathrm{~nm}$ excitation and emission filters respectively) at $250 \times$ and $400 \times$ magnification. Oocytes were considered fertilized when at least one decondensed sperm head and/or a fully formed pronucleus were identified (Figure 2) [22].

\subsection{Evaluation of Oocyte ROS Production and Oxidative Activity}

ROS production and oxidative activity were measured in immature and matured COCs. Oocytes were denuded and incubated at $37^{\circ} \mathrm{C}$ in PBS supplemented with $0.3 \%(w / v) ~ B S A$ in the presence of the respective fluoro-
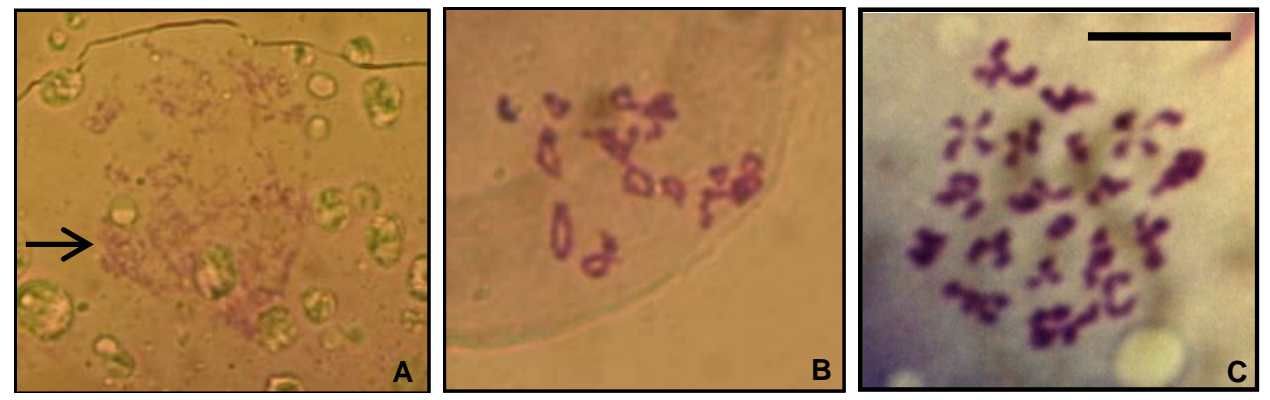

Figure 1. Oocytes stained with Giemsa, scale bar represents $10 \mu \mathrm{m}$. (A) Filamentous chromatin located throughout the area of the germinal vesicle. Arrow indicates filamentous chromatin; (B) Bivalent chromosomes in an oocyte at the first metaphase stage (MI); (C) Haploid set of chromosomes in an oocyte at the second methaphase stage (MII).
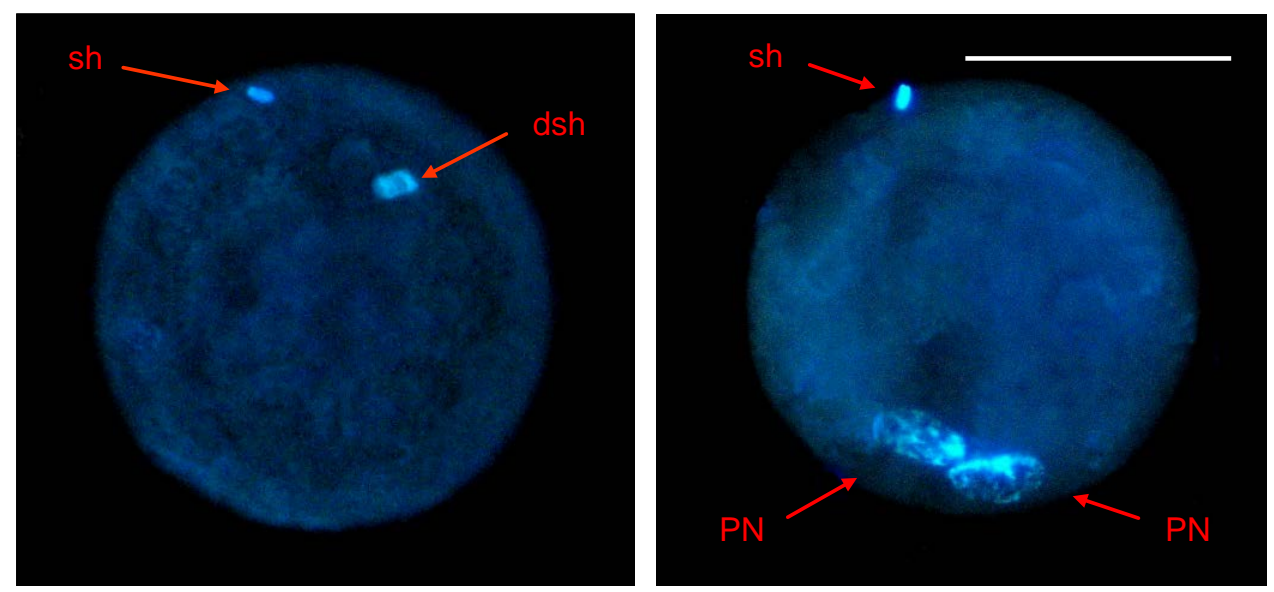

Figure 2. Fertilized zygotes stained with Hoechst 33,342 fluorochrome (sh: sperm head, dsh: decondensed sperm head, PN: pronucleus). The scale bar represents $50 \mu \mathrm{m}$. 
chromes.

To measure ROS level, denuded oocytes were incubated with $5 \mu \mathrm{M}$ 2',7'-dichlorodihydrofluorescein diacetate (DCHF-DA) for $30 \mathrm{~min}$ [29] [30].

To measure esterase activity, denuded oocytes were incubated with $0.12 \mu \mathrm{M}$ fluorescein diacetate (FDA) for $15 \mathrm{~min}$.

To measure oxidative activity, denuded oocytes were incubated with $20 \mu \mathrm{M}$ 2,3,4,5,6-pentafluorodihydrotetramethylrosamine (Redox-Sensor Red CC1) for $30 \mathrm{~min}$.

After exposure to the respective fluorochrome, oocyte samples were washed in PBS supplemented with $0.3 \%$ (w/v) BSA and mounted on glass slides. Fluorescence was measured using digital microphotographs obtained with an epifluorescence microscope using 450 - $490 \mathrm{~nm}$ and $520 \mathrm{~nm}$ excitation and emission filters respectively for DCHF-DA and FDA, and $546 \mathrm{~nm}$ and $590 \mathrm{~nm}$ excitation and emission filters respectively for Redox-Sensor Red CC1. All microphotographs were analysed using Image J 1240 software (Research Services Branch, National Institute of Mental Health, Bethesda, MD, USA), measuring the brightness of each oocyte.

The fluorescence detected by DCHF-DA is dependent on esterase activity. The ratio between the brightness of each oocyte measured by DCHF-DA and the mean brightness detected by FDA in each COC class and treatment was therefore considered a better indicator of the oocyte ROS level [30] [31]. ROS production and oxidative activity were expressed in arbitrary units per oocyte per min.

\subsection{Statistical Analysis}

Non-parametric values were recorded as percentages and compared using the Chi-squared test. Parametric values were reported as means \pm SD and comparisons were made by ANOVA. Significance was set at $\mathrm{P}<0.05$.

\section{Results}

\subsection{Experiment 1: Analysis of Porcine Follicular Fluid}

The $\mathrm{pH}$ and glucose concentration of the follicular fluid decreased in a time-dependent manner $(\mathrm{P}<0.05)$ and were lower when ovaries were preserved at higher temperatures $(\mathrm{P}<0.05$, Figure 3(a) and Figure 3(b)).

Lactate concentration, on the other hand, showed a slight but significant increase as storage time increased ( $\mathrm{P}<$ $0.05)$ and was higher when ovaries were preserved at higher temperatures $(\mathrm{P}<0.05$, Figure $3(\mathrm{c}))$.

\subsection{Experiment 2: Analysis of Immature Oocyte Quality}

The rate of immature live oocytes, oocytes in GV stage and oocyte oxidative activity decreased as storage time increased $(\mathrm{P}<0.05)$. The rate of immature live oocytes was lower when ovaries were preserved at $15^{\circ} \mathrm{C}(\mathrm{P}<$ 0.05 , Figure $4(\mathrm{a})$ ), but those which were in GV stage did not vary between ovary storage temperatures (Figure 4). On the contrary, oxidative activity increased in a temperature-dependent manner $(\mathrm{P}<0.05$, Figure 4(d)). ROS levels increased in time and temperature-dependent manners ( $\mathrm{P}<0.05$, Figure 4(c)).

\subsection{Experiment 3: Evaluation of Oocyte Nuclear Maturation}

The percentage of oocyte nuclear maturation decreased when ovaries storage time increased and when ovaries were preserved at lower temperatures $(\mathrm{P}<0.05$, Figure 5).

\subsection{Experiment 4: Evaluation of Oocyte Fertilization, ROS Production and Oxidative Activity}

Nuclear maturation rates reached the highest values when ovaries were stored at $25^{\circ} \mathrm{C}$ for $2 \mathrm{~h}$ and at $35^{\circ} \mathrm{C}$ for 2 and $4 \mathrm{~h}$ (Figure 5), thus, oocyte fertilization was evaluated in these groups to verify if temperature affects oocyte quality. The percentage of fertilized oocytes was calculated as the ratio between the number of oocytes with at least one decondensed sperm head and/or a fully formed pronucleus and the total number of immature oocytes cultured. As expected, we observed a detrimental effect on oocyte fertilization due to a longer storage of the ovaries at $35^{\circ} \mathrm{C}(\mathrm{P}<0.05)$. However, lowering the storage temperature to $25^{\circ} \mathrm{C}$ for $2 \mathrm{~h}$ did not affect oocyte fertilization (Figure 6).

ROS level and oxidative activity showed no differences between the three conditions evaluated after in vitro 


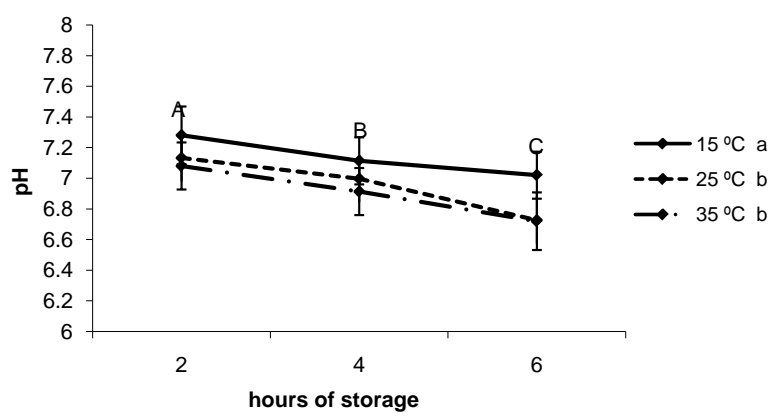

(a)

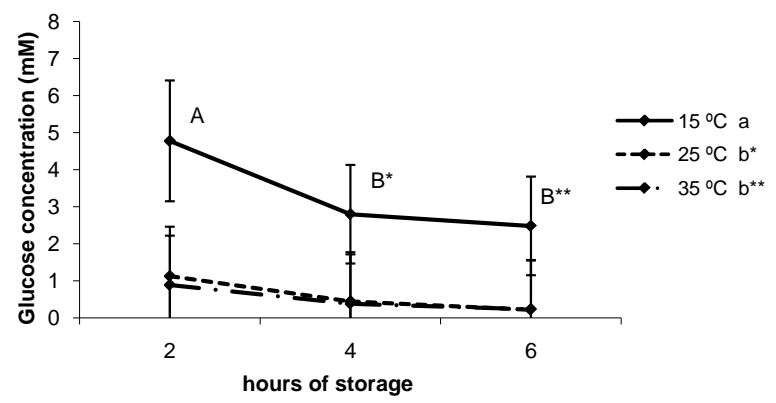

(b)

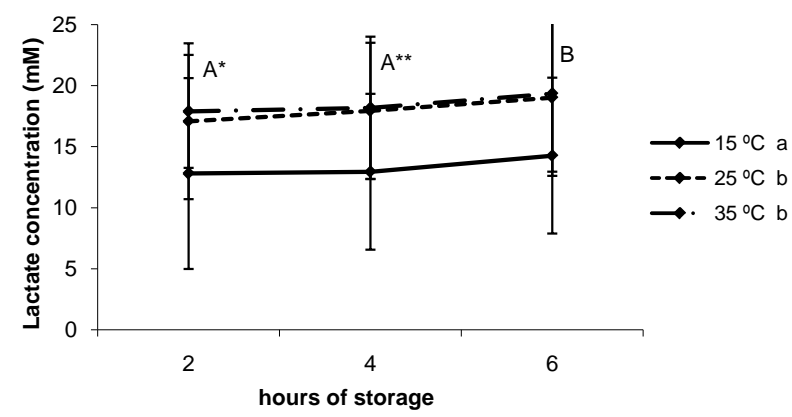

(c)

Figure 3. (a) $\mathrm{pH}$ of the follicular fluid after thestorage of ovaries for different times and at different temperatures. ${ }^{\mathrm{a}, \mathrm{b}, \mathrm{c}}$ Different superscripts indicate significant differences between storage temperatures $(\mathrm{P}<0.05)$. ${ }^{\mathrm{A}, \mathrm{B}, \mathrm{C}}$ Different superscripts indicate significant differences between storage times at the same temperature $(\mathrm{P}<0.05) . \mathrm{n}=40$ - 45 measurements for each value. Experiments were repeated three times. Data are presented as mean $\pm \mathrm{SD}$; (b) Glucose concentration in the follicular fluid after the storage of ovaries for different times and at different temperatures. ${ }^{\text {a,b and }{ }^{*}, * *}$ Different superscripts indicate significant differences between storage temperatures $(\mathrm{P}<0.05$ and $\mathrm{P}<0.1$ respectively). ${ }^{\mathrm{A}, \mathrm{B} \text { and }}{ }^{* * * *}$ Different superscripts indicate significant differences between storage times at the same temperature $(\mathrm{P}<0.05$ and $\mathrm{P}<0.1$, respectively). $\mathrm{n}=40-45$ measurements for each value. Experiments were repeated three times. Data are presented as mean $\pm \mathrm{SD}$; (c) Lactate concentration in the follicular fluid after thestorage of ovaries for different times and at different temperatures. ${ }^{\mathrm{a}, \mathrm{b}}$ Different superscripts indicate significant differences between storage temperatures $(\mathrm{P}<0.05)$. ${ }^{A, B}$ and ${ }^{* * * *}$ Different superscripts indicate significant differences between storage times at the same temperature $(\mathrm{P}<0.05$ and $\mathrm{P}<0.1$, respectively). $\mathrm{n}=40-45$ measurements for each value. Experiments were repeated three times. Data are presented as mean $\pm \mathrm{SD}$. 


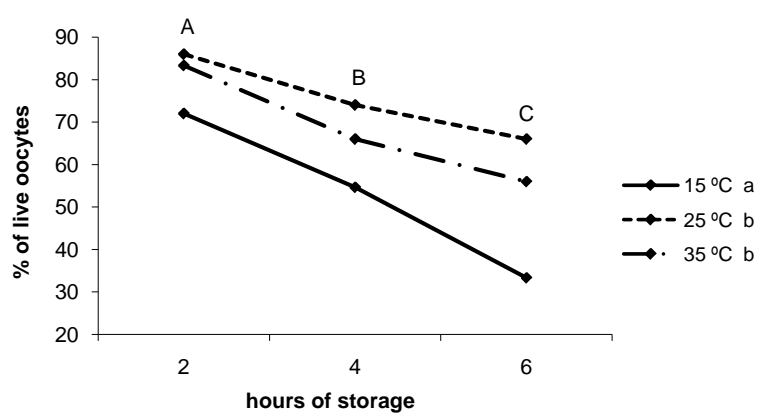

(a)

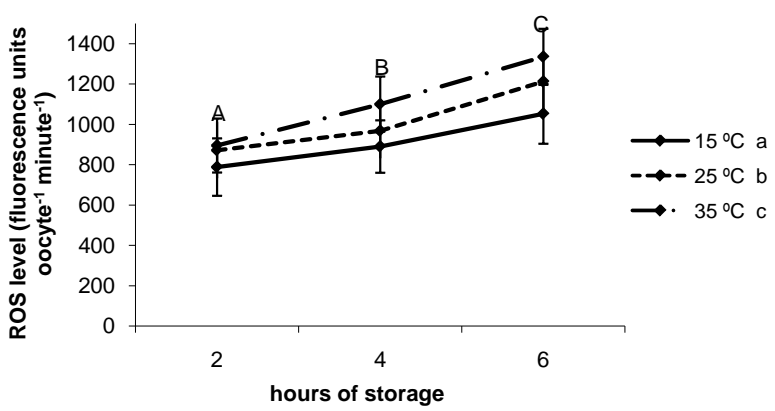

(c)

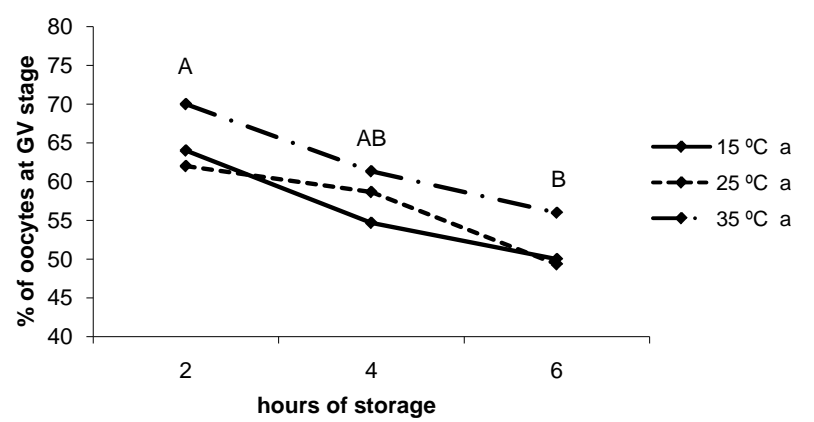

(b)

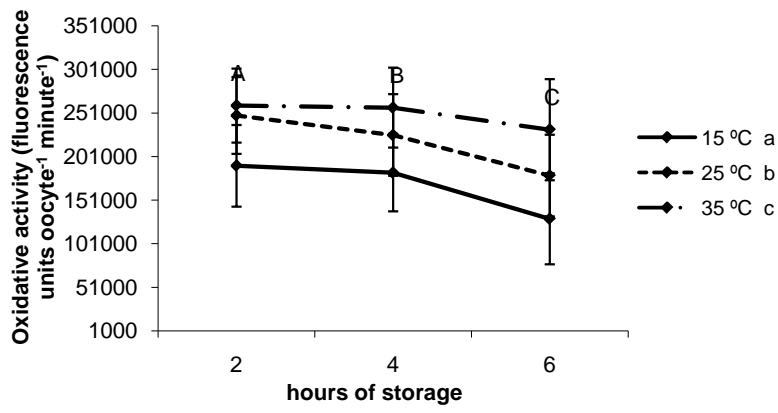

(d)

Figure 4. (a) Percentages of live oocytes recovered from ovaries stored for different times and at different temperatures. ${ }^{\mathrm{a}, \mathrm{b}}$ Different superscripts indicate significant differences between storage temperatures $(\mathrm{P}<0.05) .{ }^{\mathrm{A}, \mathrm{B}, \mathrm{C}}$ Different superscripts indicate significant differences between storage times at the same temperature $(\mathrm{P}<0.05) . \mathrm{n}=145-150$ oocytes for each value. Experiments were repeated three times; (b) Percent incidence of immature oocytes in the germinal vesicle (GV) stage recovered from ovaries stored for different times and at different temperatures. ${ }^{a}$ The same superscript indicates no significant differences between storage temperatures. ${ }^{\mathrm{A}, \mathrm{B}}$ Different superscripts indicate significant differences between storage times at the same temperature $(\mathrm{P}<0.05) . \mathrm{n}=145$ - 150 oocytes for each value. Experiments were repeated three times; (c) Reactive oxygen species (ROS) level per immature oocyte recovered from ovaries stored for different times and at different temperatures. ${ }^{a, b, c}$ Different superscripts indicate significant differences between storage temperatures $(\mathrm{P}<0.05)$. ${ }^{\mathrm{A}, \mathrm{B}, \mathrm{C}} \mathrm{Different}$ superscripts indicate significant differences between storage times at the same temperature $(P<0.05) . n=42-45$ oocytes for each value. Experiments were repeated three times. Data are presented as mean \pm SD. (d). Oxidative activity of immature oocytes recovered from ovaries stored for different times and at different temperatures. ${ }^{a, b, c}$ Different superscripts indicate significant differences between storage temperatures $(\mathrm{P}<0.05) .{ }^{\mathrm{A}, \mathrm{B}, \mathrm{C}}$ Different superscripts indicate significant differences between storage times at the same temperature $(P<0.05) . n=43-45$ oocytes for each value. Experiments were repeated three times. Data are presented as mean \pm SD.

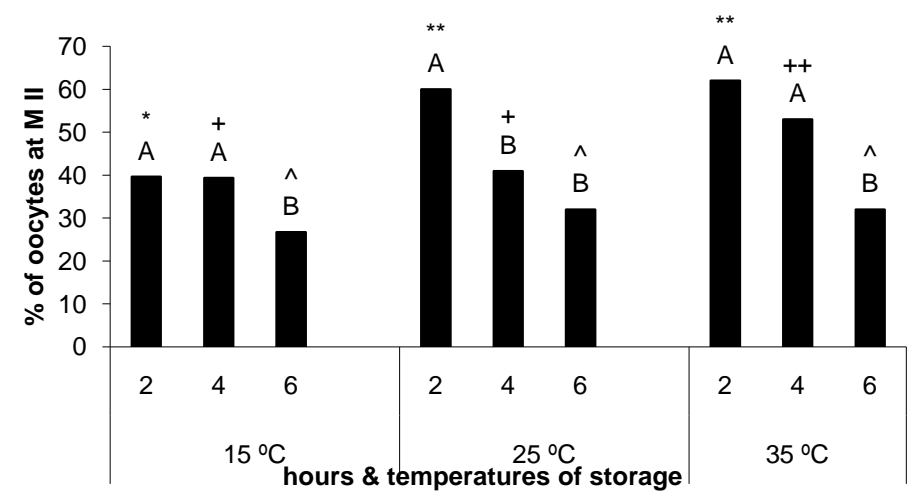

Figure 5. Percentage of oocytes reaching metaphase II (M II) after maturation of cumulus-oocyte complexes recovered from ovaries stored for different times and at different temperatures. ${ }^{* * * ;+,++;}$ Different superscripts over bars indicate significant differences between storage temperatures at the same time $(\mathrm{P}<0.05)$ and ${ }^{\mathrm{A}, \mathrm{B}}$ between storage times at the same temperature $(\mathrm{P}<0.05) . \mathrm{n}=143-150$ oocytes for each bar. Experiments were repeated three times. 


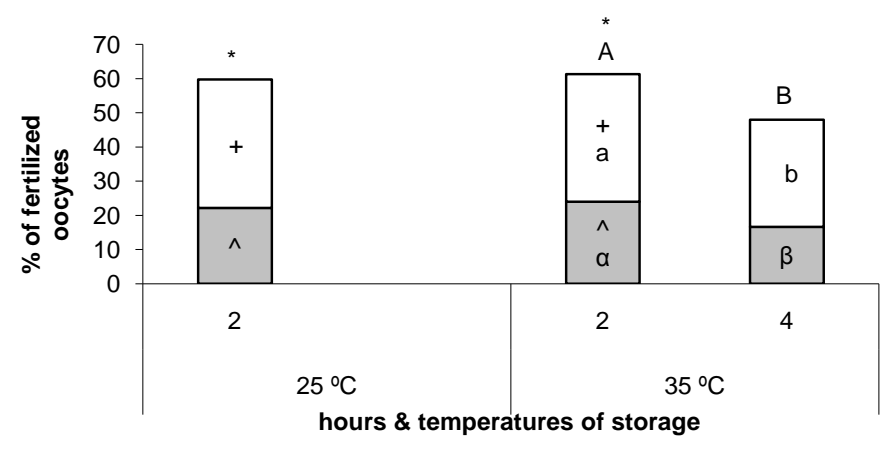

口Decondensed sperm head aPronuclear formation

\begin{abstract}
Figure 6. Percentage of oocytes with mature cytoplasm after maturation of cumulus-oocyte complexes recovered from ovaries stored for different times and at different temperatures, as evaluated by sperm head decondensation and/or pronucleus formation. ${ }^{* ;+;}$ The same superscript over bars indicates no significant differences between storage temperatures at the same time. ${ }^{\mathrm{A}, \mathrm{B} ; \mathrm{a}, \mathrm{b} ; \alpha, \beta}$ Different superscripts over bars indicate significant differences between storage times at the same temperature $(\mathrm{P}<0.05) . \mathrm{n}=148$ - 150 oocytes for each bar. Experiments were repeated three times.
\end{abstract}

maturation (Table 1). ROS levels were lower than those corresponding to the respective immature oocytes, while the oxidative activity was higher (data not shown).

\title{
4. Discussion
}

The modification of the physiological composition of the follicular fluid due to the transport of porcine ovaries under ischemic conditions may induce changes in immature oocyte quality, causing a negative impact on maturation. Coinciding with previous studies in pigs [7], we observed a decrease in the $\mathrm{pH}$ of the follicular fluid throughout ovary storage, with a more pronounced tendency at higher temperatures. In coincidence, glucose concentration decreased while lactate concentration increased, therefore suggesting that anaerobic glycolysis is the main fate for the glucose consumed by the follicular cells of the antral follicle. In our experiments, the glycolytic pathway consumed about $80 \%$ of the total glucose content in the follicular fluid (4.4 - $4.7 \mathrm{mM} \mathrm{[10])}$ within $2 \mathrm{~h}$ when the ovaries were stored at temperatures between $25^{\circ} \mathrm{C}$ and $35^{\circ} \mathrm{C}$.

It has been reported that ovary storage during 6 to $12 \mathrm{~h}$ and at temperatures lower than $15^{\circ} \mathrm{C}$ has a detrimental effect on the maturation rates of porcine oocytes [7]. It has also been demonstrated that overnight storage at $15^{\circ} \mathrm{C}-20^{\circ} \mathrm{C}$ of bovine ovaries leads to lower gene expression [32]. In our study, the storage of ovaries for 4 and $6 \mathrm{~h}\left(\right.$ at $15^{\circ} \mathrm{C}, 25^{\circ} \mathrm{C}$ and $35^{\circ} \mathrm{C}$ ) resulted in a decreased rate of immature live oocytes. Furthermore, a significant decrease in the percentage of oocytes at the germinal vesicle stage was observed as storage time increased. As regards storage temperature, when ovaries were stored at $15^{\circ} \mathrm{C}$, the rate of live oocytes decreased in comparison to that observed at $25^{\circ} \mathrm{C}$ and $35^{\circ} \mathrm{C}$ (during storage for 2,4 and $6 \mathrm{~h}$ ). Therefore, both ovary storage time and temperature affect the rate of immature live oocytes and maturation rates. However, temperature does not seem to affect the nuclear stage of the oocytes recovered. This suggests a time-dependent increase in oocyte early germinal vesicle breakdown. It has been observed that porcine oocytes can resume meiosis inside the follicle in a phenomenon known as precocious resumption of meiosis [22], an event also described in mouse, ovine and bovine ovarian oocytes committed to atresia [33]-[36]. The variation of $\mathrm{pH}$, glucose and lactate concentrations in the follicular fluid could trigger the precocious resumption of meiosis in the porcine oocyte.

Immature oocytes showed higher ROS levels when recovered from ovaries stored for a long time and high temperature, while oocyte oxidative activity decreased in a time-dependent manner when ovaries were stored at lower temperatures. The increase in oocyte nuclear DNA fragmentation was demonstrated during ovary storage for a time period longer than $2 \mathrm{~h}$ [7]. The increased ROS level recorded in the present work might mediate nucleic acid damage in oocytes, impairing oocyte maturation and may also be involved in the precocious germinal vesicle breakdown and the lower oocyte vitality observed. On the other hand, when ovaries were stored at $15^{\circ} \mathrm{C}$ 
Table 1. Reactive oxygen species (ROS) level and oxidative activity per oocyte matured after storage of ovaries for different times and at different temperatures. Values are fluorescence units oocyte ${ }^{-1}$ minute $^{-1}$. ${ }^{a}$ The same superscript indicates no significant differences within the same line. $n=42$ - 45 oocytes for each value. Experiments were repeated three times. Data are presented as mean \pm SD.

\begin{tabular}{cccc}
\hline & \multicolumn{3}{c}{ Ovary storage conditions } \\
\cline { 2 - 4 } & $25^{\circ} \mathrm{C} 2 \mathrm{~h}$ & $35^{\circ} \mathrm{C} 2 \mathrm{~h}$ & $35^{\circ} \mathrm{C} 4 \mathrm{~h}$ \\
\hline ROS level & $717.26 \pm 109.9^{\mathrm{a}}$ & $675.4 \pm 67^{\mathrm{a}}$ & $631.56 \pm 121.6^{\mathrm{a}}$ \\
Oxidative activity & $320,503 \pm 24529.1^{\mathrm{a}}$ & $310,549 \pm 27724.5^{\mathrm{a}}$ & $306,664 \pm 29142.8^{\mathrm{a}}$ \\
\hline
\end{tabular}

maturation rates were also lower, but ROS level did not increase. This impairment in maturation could be due to the low oxidative activity, which seems to be related to a reduction in oocyte vitality, or to the disruption of the meiotic spindle, the loss of membrane integrity and the oocyte zone hardening, which have been suggested in previous studies [7] [8]. These alterations may affect oocyte maturation without ROS participation.

This work demonstrates the relationship between oocyte quality and ovaries storage time and temperature for the first time. Oocyte meiotic competence may be maintained when ovaries are stored at $25^{\circ} \mathrm{C}$ for $2 \mathrm{~h}$ and at $35^{\circ} \mathrm{C}$ for 2 and $4 \mathrm{~h}$, as demonstrated by the ability of the gametes to reach metaphase II nuclear stage after in vitro maturation. However, the most adequate storage conditions to allow both nuclear and cytoplasmic maturation are $25^{\circ} \mathrm{C}$ and $35^{\circ} \mathrm{C}$ for $2 \mathrm{~h}$. The increase in the ovaries storage time has a deleterious effect on oocyte quality, not only due to the acidification of the follicular fluid, caused in part by lactate accumulation, but also because of the increase in the endogenous ROS level and the decrease in the oxidative activity of the oocytes. The combination of these factors leads to a precocious germinal vesicle breakdown in immature oocytes and even to gamete death. On the other hand, the decrease in the transport temperature causes a decrease in the oxidative activity and in the immature oocytes vitality, without affecting any of the other parameters evaluated.

Our manuscript verifies the fact that the storage of porcine ovaries for long periods of time and low temperatures impairs oocyte in vitro maturation, but it also contributes to understand the effect of ovaries storage in the morphological and functional features of immature oocytes, which had not been evaluated up to date.

\section{Conclusion}

Most of the glucose in the follicular fluid seems to be used by granulosa and cumulus cells in the glycolytic pathway, producing the accumulation of lactate during the first $2 \mathrm{~h}$ of storage of porcine ovaries at $25^{\circ} \mathrm{C}$ and $35^{\circ} \mathrm{C}$. The resulting decrease in the $\mathrm{pH}$ of the follicular fluid together with the increase in ROS level in immature oocytes generated by the storage of ovaries at $25^{\circ} \mathrm{C}$ and $35^{\circ} \mathrm{C}$ for more than $2 \mathrm{~h}$ seems to cause enough oocyte injury to impair in vitro maturation and even to cause gamete death. A decrease in the oxidative activity caused by the long-time and/or low temperature of storage may result in a decrease in oocyte vitality. In the porcine species, short time and high temperature transport conditions of ovaries are the most adequate storage conditions to maintain oocyte quality as well as meiotic and cytoplasmic developmental competence.

\section{Acknowledgements}

The authors thank the Japanese International Cooperation Agency (JICA) for technology transfer and equipment, the Porkind abattoir for ovaries, Astra Laboratories for ultra-pure water, ETC Internacional S.A. for donation of cell culture products and Vet. Sergio Morado for his technical assistance.

\section{Conflicts of Interest}

The authors declare they have no conflicts of interest that might impede their impartiality with respect to the work performed.

\section{Funding}

This work was funded by the University of Buenos Aires (grant number UBACyT V007).

\section{References}

[1] Guignot, F., Bezard, J. and Palmer, E. (1999) Effect of Time during Transport of Excised Mare Ovaries on Oocyte 
Recovery Rate and Quality after in Vitro Maturation. Theriogenology, 52, 757-766. http://dx.doi.org/10.1016/S0093-691X(99)00169-7

[2] Moodie, G. and Graham, E. (1989) The Effect of Incubating Sheep Ovaries for Various Times and Temperatures on Oocyte Maturation Rates in Vitro. Biology of Reproduction, 40, 53.

[3] Evecen, M., Cirit, U., Demir, K., Ozdas, O.B., Tas, M., Birler, S. and Pabuccuoglu, S. (2010) Effects of Estrous Cycle Stage and Transport Temperature of Ovaries on in Vitro Maturation of Canine Oocytes. Animal Reproduction Science, 117, 160-165. http://dx.doi.org/10.1016/j.anireprosci.2009.03.004

[4] Yang, N., Lu, K. and Gordon, I. (1990) In Vitro Fertilization (IVF) and Culture (IVC) of Bovine Oocytes from Stored Ovaries. Theriogenology, 33, 352. http://dx.doi.org/10.1016/0093-691X(90)90776-P

[5] Solano, R., De Armas, R., Pupo, C. and Castro, F. (1994) Short Term Preservation of Intrafollicular Oocytes at 4 C. Theriogenology, 41, 299. http://dx.doi.org/10.1016/S0093-691X(05)80209-2

[6] Evecen, M., Cirit, U., Demir, K., Karaman, E., Hamzaoglu, A.I. and Bakirer, G. (2009) Developmental Competence of Domestic Cat Oocytes from Ovaries Stored at Various Durations at $4^{\circ} \mathrm{C}$ Temperature. Animal Reproduction Science, 116, 169-172. http://dx.doi.org/10.1016/j.anireprosci.2009.01.006

[7] Wongsrikeao, P., Otoi, T., Karja, N.W., Agung, B., Nii, M. and Nagai, T. (2005) Effects of Ovary Storage Time and Temperature on DNA Fragmentation and Development of Porcine Oocytes. Journal of Reproduction and Development, 51, 87-97. http://dx.doi.org/10.1262/jrd.51.87

[8] Lin, Y.A., Tsai, H.B., Liao, M.H. and Chen, M.C. (2010) Effect of Preserving Condition of Porcine Ovaries on the Development of in Vitro Matured Oocytes. Reproduction in Domestic Animals, 46, 333-337. http://dx.doi.org/10.1111/j.1439-0531.2010.01671.x

[9] Nelson, D. and Cox, M. (2005) Enzymes. In: Nelson, D. and Cox, M., Eds., Lehninger Principles of Biochemistry, 4th Edition, W. H. Freeman and Company, New York, 190-237.

[10] Chang, S.C., Jones, J.D., Ellefson, R.D. and Ryan, R.J. (1976) The Porcine Ovarian Follicle: I. Selected Chemical Analysis of Follicular Fluid at Different Developmental Stages. Biology of Reproduction, 15, 321-328. http://dx.doi.org/10.1095/biolreprod15.3.321

[11] Orsi, N.M., Gopichandran, N., Leese, H.J., Picton, H.M. and Harris, S.E. (2005) Fluctuations in Bovine Ovarian Follicular Fluid Composition throughout the Oestrous Cycle. Reproduction, 129, 219-228. http://dx.doi.org/10.1530/rep.1.00460

[12] Nelson, D. and Cox, M. (2005) Glycolysis, Gluconeogenesis, and the Pentose Phosphate Pathway. In: Nelson, D. and Cox, M., Eds., Lehninger Principles of Biochemistry, 4th Edition. W. H. Freeman and Company, New York, 521-559.

[13] Fatehi, A.N., Roelen, B.A., Colenbrander, B., Schoevers, E.J., Gadella, B.M., Beverst, M.M. and van den Hurk, R. (2005) Presence of Cumulus Cells during in Vitro Fertilization Protects the Bovine Oocyte against Oxidative Stress and Improves First Cleavage but Does Not Affect Further Development. Zygote, 13, 177-185. http://dx.doi.org/10.1017/S0967199405003126

[14] Choi, W.J., Banerjee, J., Falcone, T., Bena, J., Agarwal, A. and Sharma, R.K. (2007) Oxidative Stress and Tumor Necrosis Factor-Alpha-Induced Alterations in Metaphase II Mouse Oocyte Spindle Structure. Fertility and Sterility, 88, 1220-1231. http://dx.doi.org/10.1016/j.fertnstert.2007.02.067

[15] Tatemoto, H., Sakurai, N. and Muto, N. (2000) Protection of Porcine Oocytes against Apoptotic Cell Death Caused by Oxidative Stress during in Vitro Maturation: Role of Cumulus Cells. Biology of Reproduction, 63, 805-810. http://dx.doi.org/10.1095/biolreprod63.3.805

[16] Zhang, X., Li, X.H., Ma, X., Wang, Z.H., Lu, S. and Guo, Y.L. (2006) Redox-Induced Apoptosis of Human Oocytes in Resting Follicles in Vitro. Journal of the Society for Gynecologic Investigation, 13, 451-458. http://dx.doi.org/10.1016/j.jsgi.2006.05.005

[17] Lopes, A.S., Lane, M. and Thompson, J.G. (2010) Oxygen Consumption and ROS Production Are Increased at the Time of Fertilization and Cell Cleavage in Bovine Zygotes. Human Reproduction, 25, 2762-2773. http://dx.doi.org/10.1093/humrep/deq221

[18] Dumollard, R., Ward, Z., Carroll, J. and Duchen, M.R. (2007) Regulation of Redox Metabolism in the Mouse Oocyte and Embryo. Development, 134, 455-465. http://dx.doi.org/10.1242/dev.02744

[19] Cunningham, J.G. and Klein, B.G. (2007) Textbook of Veterinary Physiology. Elsevier Science Health Science Division.

[20] Barham, D. and Trinder, P. (1972) An Improved Colour Reagent for the Determination of Blood Glucose by the Oxidase System. Analyst, 97, 142-145. http://dx.doi.org/10.1039/an9729700142

[21] Gutnisky, C., Dalvit, G.C., Pintos, L.N., Thompson, J.G., Beconi, M.T. and Cetica, P.D. (2007) Influence of Hyaluronic Acid Synthesis and Cumulus Mucification on Bovine Oocyte in Vitro Maturation, Fertilisation and Embryo Development. Reproduction, Fertility and Development, 19, 488-497. http://dx.doi.org/10.1071/RD06134 
[22] Alvarez, G.M., Dalvit, G.C., Achi, M.V., Miguez, M.S. and Cetica, P.D. (2009) Immature Oocyte Quality and Maturational Competence of Porcine Cumulus-Oocyte Complexes Subpopulations. Biocell, 33, 167-177.

[23] Hoppe, R. and Bavister, B. (1984) Evaluation of the Fluorescein Diacetate (FDA) Vital Dye Viability Test with Hamster and Bovine Embryos. Animal Reproduction Science, 6, 323-325. http://dx.doi.org/10.1016/0378-4320(84)90010-1

[24] Luttmer, S. and Longo, F. (1986) Examination of Living and Fixed Gametes and Early Embryos Stained with Supravital Fluorochromes. Gamete Research, 15, 267-283. http://dx.doi.org/10.1002/mrd.1120150308

[25] Abeydeera, L.R., Wang, W.H., Prather, R.S. and Day, B.N. (2001) Effect of Incubation Temperature on in Vitro Maturation of Porcine Oocytes: Nuclear Maturation, Fertilisation and Developmental Competence. Zygote, 9, 331-337. http://dx.doi.org/10.1017/S0967199401001381

[26] Hancock, J. and Hovell, G. (1959) The Collection of Boar Semen. The Veterinary Record, 71, 664-665.

[27] Abeydeera, L.R. and Day, B.N. (1997) In Vitro Penetration of Pig Oocytes in a Modified Tris-Buffered Medium: Effect of BSA, Caffeine and Calcium. Theriogenology, 48, 537-544. http://dx.doi.org/10.1016/S0093-691X(97)00270-7

[28] Pereira, R.J., Tuli, R.K., Wallenhorst, S. and Holtz, W. (2000) The Effect of Heparin, Caffeine and Calcium Ionophore A23187 on in Vitro Induction of the Acrosome Reaction in Frozen-Thawed Bovine and Caprine Spermatozoa. Theriogenology, 54, 185-192. http://dx.doi.org/10.1016/S0093-691X(00)00340-X

[29] LeBel, C., Ischiropoulos, H. and Bondy, S. (1992) Evaluation of the Probe 2',7'-Dichlorofluorescein as an Indicator of Reactive Oxygen Species Formation and Oxidative Stress. Chemical Research in Toxicology, 5, 227-231. http://dx.doi.org/10.1021/tx00026a012

[30] Morado, S.A., Cetica, P.D., Beconi, M.T. and Dalvit, G.C. (2009) Reactive Oxygen Species in Bovine Oocyte Maturation in Vitro. Reproduction, Fertility and Development, 21, 608-614. http://dx.doi.org/10.1071/RD08198

[31] Lane, M., Maybach, J.M. and Gardner, D.K. (2002) Addition of Ascorbate during Cryopreservation Stimulates Subsequent Embryo Development. Human Reproduction, 17, 2686-2693. http://dx.doi.org/10.1093/humrep/17.10.2686

[32] Somfai, T., Imai, K., Kaneda, M., Akagi, S., Watanabe, S., Haraguchi, S., Mizutani, E., Dang-Nguyen, T.Q., Inaba, Y., Geshi, M. and Nagai, T. (2011) The Effect of Ovary Storage and in Vitro Maturation on mRNA Levels in Bovine Oocytes; A Possible Impact of Maternal ATP1A1 on Blastocyst Development in Slaughterhouse-Derived Oocytes. Journal of Reproduction and Development, 57, 723-730. http://dx.doi.org/10.1262/jrd.11-020H

[33] Oakberg, E.F. (1979) Follicular Growth and Atresia in the Mouse. In Vitro, 15, 41-49. http://dx.doi.org/10.1007/BF02627078

[34] Murdoch, W.J. (1992) Comparative Morphometry and Steroidogenic Function of Antral Ovine Follicles Destined for Ovulation or Atresia. Domestic Animal Endocrinology, 9, 219-224. http://dx.doi.org/10.1016/0739-7240(92)90035-V

[35] Assey, R.J., Hyttel, P., Greve, T. and Purwantara, B. (1994) Oocyte Morphology in Dominant and Subordinate Follicles. Molecular Reproduction and Development, 37, 335-344. http://dx.doi.org/10.1002/mrd.1080370313

[36] Cetica, P.D., Dalvit, G.C. and Beconi, M.T. (1999) Study of Evaluation Criteria Used for in Vitro Bovine Oocyte Selection and Maturation. Biocell, 23, 125-133. 
Scientific Research Publishing (SCIRP) is one of the largest Open Access journal publishers. It is currently publishing more than 200 open access, online, peer-reviewed journals covering a wide range of academic disciplines. SCIRP serves the worldwide academic communities and contributes to the progress and application of science with its publication.

Other selected journals from SCIRP are listed as below. Submit your manuscript to us via either submit@scirp.org or Online Submission Portal.
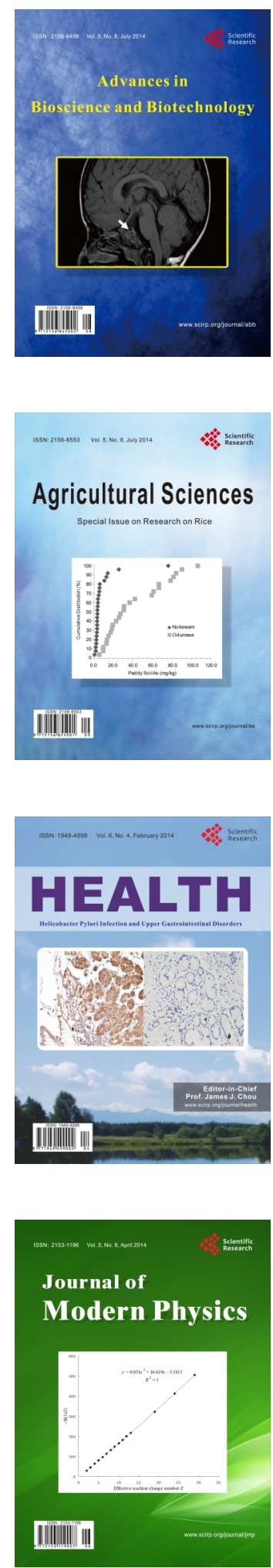
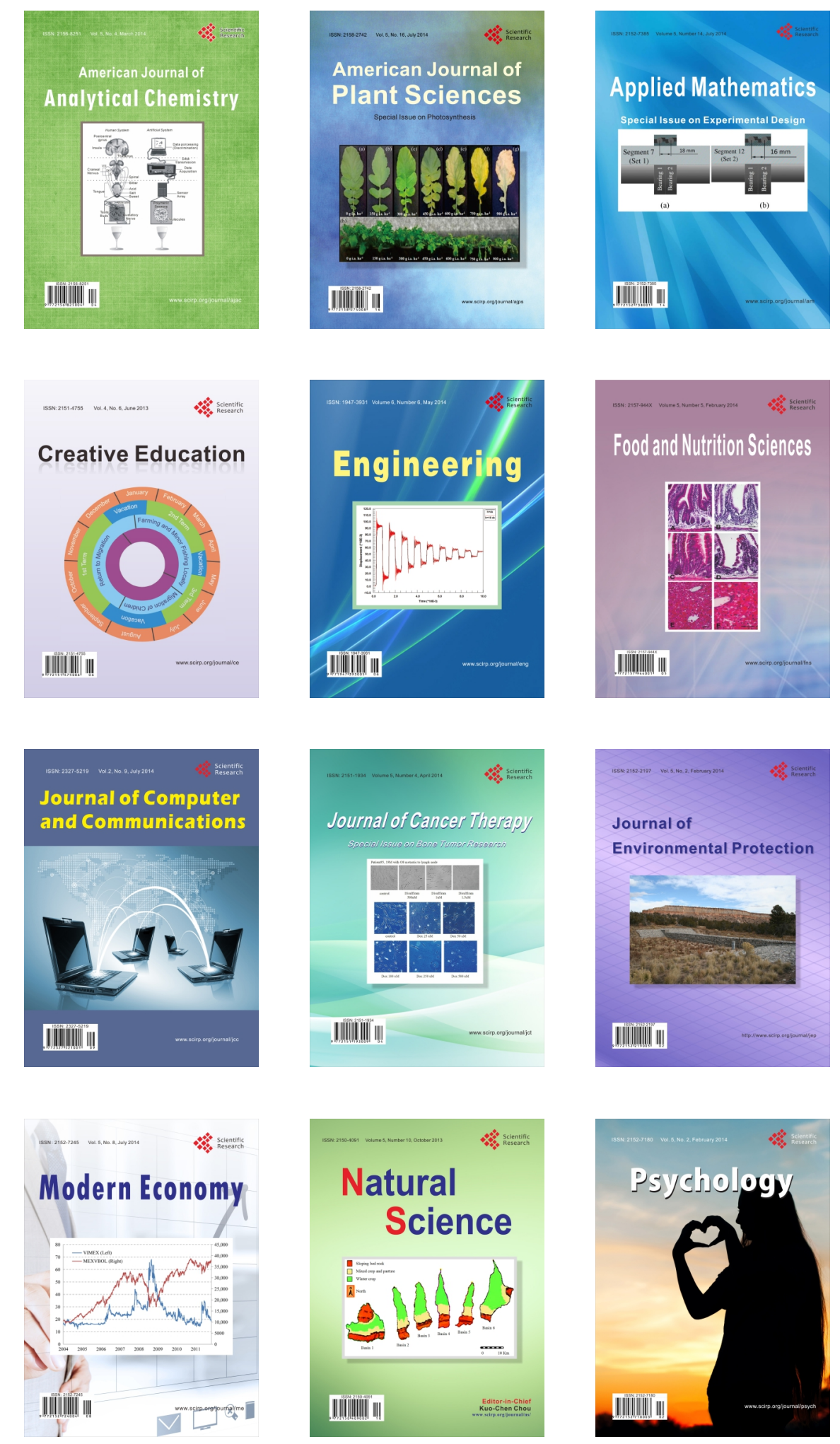